\title{
Pharmacokinetics of the Oral Selective CXCR2 Antagonist AZD5069: A Summary of Eight Phase I Studies in Healthy Volunteers
}

\author{
Marie Cullberg ${ }^{1} \cdot$ Cecilia Arfvidsson $^{1} \cdot$ Bengt Larsson $^{1} \cdot$ Anna Malmgren $^{2} \cdot$ \\ Patrick Mitchell $^{3} \cdot$ Ulrika Wählby Hamrén $^{1} \cdot$ Heather Wray ${ }^{1}$
}

Published online: 31 May 2018

(C) The Author(s) 2018

\begin{abstract}
Objective The aim of this study was to summarise the pharmacokinetic findings from eight phase I studies in healthy volunteers given oral AZD5069, a selective smallmolecule CXCR2 antagonist.

Methods 240 healthy volunteers across eight phase I studies received single $(0.1-200 \mathrm{mg})$ or multiple once- or twice-daily (10-120 mg) oral AZD5069 as solution, suspension, capsules or tablets. Pharmacokinetics were evaluated using non-compartmental analysis methods.

Results AZD5069 was rapidly absorbed (time to maximum concentration $\sim 2 \mathrm{~h}$ ) under fasting conditions. A high-fat, high-calorie meal delayed and reduced the peak plasma AZD5069 concentration $\left(C_{\max }\right)$ by $50 \%$, but total exposure (AUC) was unchanged (fed:fasting geometric mean ratio 90\% confidence interval within 0.80-1.25). The plasma concentration of AZD5069 declined with an initial half-life of $4 \mathrm{~h}$ and terminal half-life of $11 \mathrm{~h}$. Steady-state plasma concentrations were achieved within 2-3 days and accumulation was $\sim 1$.1-fold with twice-daily dosing. Systemic exposure was approximately proportional to dose.
\end{abstract}

Electronic supplementary material The online version of this article (https://doi.org/10.1007/s40268-018-0236-x) contains supplementary material, which is available to authorized users.

Marie Cullberg

marie.cullberg@astrazeneca.com

1 Early Clinical Development, IMED Biotech Unit, AstraZeneca, Pepparedsleden 1, Mölndal, 43183 Gothenburg, Sweden

2 Respiratory, Inflammation and Autoimmunity, IMED Biotech Unit, AstraZeneca, Gothenburg, Sweden

3 Early Clinical Development, IMED Biotech Unit, AstraZeneca, Boston, USA
Intra- and inter-subject variability in AUC was 3-11 and $29-64 \%$, respectively. Less than 5\% of the AZD5069 dose was excreted as parent drug in the urine. Elderly subjects had 39\% higher AZD5069 AUC and 21\% higher $C_{\max }$ than younger adults. Japanese subjects had similar or slightly higher exposure to AZD5069 than Caucasian subjects. Coadministration with ketoconazole resulted in 2.1-fold higher AUC and 1.6-fold higher $C_{\max }$. All formulations had similar bioavailability.

Conclusions AZD5069 demonstrated predictive linear pharmacokinetics with low intra- and moderate inter-subject variability and no major influences from ethnicity, age, food or formulation. Half-life data indicated suitability for twice-daily dosing.

Clinicaltrials.gov identifiers NCT00953888, NCT01051 505, NCT01083238, NCT01100047, NCT01332903, NCT 01480739, NCT01735240, NCT01989520.

\section{Key Points}

AZD5069 has predictive, linear pharmacokinetics with no major influences of ethnicity, age, food or formulation.

AZD5069 half-life data support twice-daily dosing. 


\section{Introduction}

AZD5069 is a selective cysteine-x-cysteine receptor 2 (CXCR2) antagonist developed as a potential treatment for inflammatory diseases, such as asthma, chronic obstructive pulmonary disease (COPD), and malignancies. CXCR2 is expressed on the surface of mainly neutrophils, but is also present on other inflammatory effector cells. CXC chemokines such as CXCL1 and CXCL8 interact with these receptors to induce neutrophil migration towards inflamed tissues [1, 2]. AZD5069 is a small molecule that has demonstrated selective and reversible antagonism of CXCR2 in human neutrophils in vitro [3]. AZD5069 inhibited binding of radiolabelled CXCL8 to human CXCR2 in vitro with an $\mathrm{IC}_{50}$ (concentration that produces $50 \%$ inhibition) value of $0.79 \mathrm{nmol} / \mathrm{L}$.

Studies in human hepatocytes, liver microsomes and a range of heterologously expressed human cytochrome P450 (CYP) enzymes have indicated that the oxidative metabolism of AZD5069 is primarily mediated by CYP3A4 and CYP2C9 isozymes, but other metabolic pathways (e.g. glucuronidation) may also play a significant role in the elimination of AZD5069 [4]. To date, AZD5069 has been studied in eight phase I studies in healthy volunteers [5-11], and in three phase II studies in inflammatory respiratory diseases [11-14].

Oral administration of AZD5069 markedly reduces sputum neutrophilia in patients with stable bronchiectasis and neutrophils in sputum and lung tissue in asthma patients at dose levels that do not affect neutrophil host defence functions $[9,12,15]$. However, no objective measures of clinical improvement emerged in the bronchiectasis study [12], nor in the recently conducted phase IIb study in severe asthma [14]. This was despite an estimated receptor occupancy of $>90 \%$ over the dosing interval (45 mg twice daily [bid]) in more than $75 \%$ of the patients [14], and significant neutrophil reductions. AZD5069 is currently under investigation in patients with cancer [16].

Here, we report the pharmacokinetic (PK) profile of AZD5069 based on the data from the eight conducted phase I studies in healthy volunteers. The objectives of these studies included characterisation of plasma and urine pharmacokinetic parameters of AZD5069, rates and routes of elimination, time to reach steady state, time and dose dependencies, diurnal variability, and the influence of intrinsic (ethnicity, age) and extrinsic (food, CYP3A inhibition and formulation) factors on AZD5069 pharmacokinetics.

\section{Methods}

\subsection{Studies}

Summaries of the study designs and clinicaltrials.gov identifiers for all studies are included in Table 1. Study flow charts are provided in Supplementary Figures S1-S8 (see electronic supplementary material [ESM]). All studies were conducted in healthy volunteer subjects. All participants provided written informed consent prior to study entry and study protocols were reviewed and approved by local Independent Ethics Committees prior to commencing studies. All studies were performed in accordance with ethical principles that have their origin in the Declaration of Helsinki, and consistent with the International Conference on Harmonisation (ICH)/Good Clinical Practice (GCP) and applicable regulatory requirements.

\subsubsection{First-in-Human Studies: Single Ascending Dose (SAD), Multiple Ascending Dose (MAD) and SAD/ $M A D$ in Japanese Subjects (JSAD/JMAD)}

The primary objective of these trials was to explore the safety and tolerability of escalating single $(0.1-200 \mathrm{mg})$ and/or twice daily doses (10-100 mg) of AZD5069. The secondary objective was to investigate AZD5069 kinetics. The studies were randomised, double-blind, parallel-group, placebo-controlled studies and were each conducted at a single centre. A safety review committee assessed available pharmacokinetic, safety and tolerability data after each cohort was dosed to determine the next dose level.

\subsubsection{Absorption, Distribution, Metabolism and Excretion Mass Balance (ADME) Study}

The primary objective of the ADME study was to characterise the pharmacokinetics, routes of excretion and metabolism of a single oral dose of $\left[{ }^{14} \mathrm{C}\right]$ AZD5069 in healthy male subjects, who received a single dose of an oral solution containing $120 \mathrm{mg} \quad\left[{ }^{14} \mathrm{C}\right]$ AZD5069 (21.6 MBq). Blood and urine samples were collected predose and, along with faeces samples, at specified intervals for up to $168 \mathrm{~h}$ after administration and were assessed for radioactivity levels to determine the mass balance of AZD5069. Plasma non-compartmental pharmacokinetic parameters were assessed on unlabelled AZD5069. 
Table 1 Key information for phase I studies in healthy volunteers

\begin{tabular}{|c|c|c|c|}
\hline $\begin{array}{l}\text { Study acronym } \\
\text { and } \\
\text { clinicaltrials.gov } \\
\text { ID }\end{array}$ & Study description & Dose/route/duration & Demographics \\
\hline $\begin{array}{l}\text { SAD } \\
\text { NCT00953888 }\end{array}$ & $\begin{array}{l}\text { Single ascending } \\
\text { dose } \\
\text { DB, PC, PG, R }\end{array}$ & $\begin{array}{l}\text { Single oral doses of AZD5069 or placebo suspension: } \\
0.1,0.5,1.65,5.45,17.99,60,120,200 \mathrm{mg}\end{array}$ & $\begin{array}{l}64 \text { males and } 5 \text { females (all } \\
\text { Caucasian), median age } \\
37 \text { years (range } 18-58 \text { ); } 45 \\
\text { on AZD5069, } 24 \text { on placebo }\end{array}$ \\
\hline $\begin{array}{l}\text { MAD } \\
\text { NCT01051505 }\end{array}$ & $\begin{array}{l}\text { Multiple ascending } \\
\text { dose } \\
\text { DB, PC, PG, R }\end{array}$ & $\begin{array}{l}\text { Oral doses of AZD5069 or placebo suspension: } \\
10,40,100 \mathrm{mg} \\
\text { Single doses on Days } 1 \text { and } 8 \text {, bid administration on Days } 2-7\end{array}$ & $\begin{array}{l}33 \text { (32 Caucasian, } 1 \text { Black) } \\
\text { male smokers, median age } \\
26 \text { years (range } 18-56) ; 25 \\
\text { on AZD5069, } 8 \text { on placebo }\end{array}$ \\
\hline $\begin{array}{l}\text { JSAD/JMAD } \\
\text { NCT01100047 }\end{array}$ & $\begin{array}{l}\text { Single and } \\
\text { multiple } \\
\text { ascending dose } \\
\text { in Japanese } \\
\text { subjects } \\
\text { DB, PC, PG, R }\end{array}$ & $\begin{array}{l}\text { Single and multiple oral doses of AZD5069 or placebo suspension: } \\
10,20,40,60,80 \mathrm{mg} \text {; and a single oral dose of } 120 \mathrm{mg} \\
\text { Single doses on Days } 1 \text { and } 11 \text {, bid administration on Days } 4-10\end{array}$ & $\begin{array}{l}63 \text { Japanese males, median age } \\
28 \text { years (range } 22-39 \text { ); } 42 \\
\text { on AZD5069, } 21 \text { on placebo }\end{array}$ \\
\hline $\begin{array}{l}\text { ADME } \\
\text { NCT01332903 }\end{array}$ & $\begin{array}{l}\text { Mass balance } \\
\text { study } \\
\text { ADME } \\
\text { OL }\end{array}$ & Single oral 120 -mg dose of $\left[{ }^{14} \mathrm{C}\right]$-radiolabelled AZD5069 solution & $\begin{array}{l}6 \text { Caucasian males, median } \\
\text { age } 54 \text { years (range } 50-65) \text {; } \\
\text { all on AZD5069 }\end{array}$ \\
\hline $\begin{array}{l}\text { NF } 24 \text { h PK } \\
\text { NCT01480739 }\end{array}$ & $\begin{array}{l}\text { Neutrophil } \\
\text { function 24-h } \\
\text { pharmacokinetic } \\
\text { study } \\
\text { DB, PC, R, XO }\end{array}$ & $\begin{array}{l}100 \mathrm{mg} \text { AZD5069 bid oral capsule and placebo capsule } \\
6 \text { days in each of } 2 \text { treatment periods }\end{array}$ & $\begin{array}{l}29 \text { males and } 1 \text { female (all } \\
\text { Caucasian), median age } \\
28 \text { years (range 19-45); } 29 \\
\text { received AZD5069 and } 29 \\
\text { received placebo }\end{array}$ \\
\hline $\begin{array}{l}\text { Food (Part A) } \\
\text { NCT01083238 }\end{array}$ & $\begin{array}{l}\text { Food effect } \\
\text { OL, R, XO }\end{array}$ & $\begin{array}{l}\text { Single oral doses of } 120 \mathrm{mg} \text { AZD5069 suspension } \\
2 \text { doses, } 1 \text { after fasting and } 1 \text { after a high fat meal }\end{array}$ & $\begin{array}{l}15 \text { Caucasian and } 1 \text { other non- } \\
\text { specific males, median age } \\
29.5 \text { years (range } 23-57 \text { ); all } \\
\text { on AZD5069 }\end{array}$ \\
\hline $\begin{array}{l}\text { Age (Part B) } \\
\text { NCT01083238 }\end{array}$ & $\begin{array}{l}\text { Age effect } \\
\text { OL }\end{array}$ & Single oral dose of $120 \mathrm{mg}$ AZD5069 suspension & $\begin{array}{l}3 \text { males and } 5 \text { females (all } \\
\text { Caucasian), median age } 68 \\
\text { (range } 65-77) ; \text { all on } \\
\text { AZD5069 }\end{array}$ \\
\hline $\begin{array}{l}\text { DDI } \\
\text { NCT01735240 }\end{array}$ & $\begin{array}{l}\text { Ketoconazole } \\
\text { CYP3A4 } \\
\text { inhibition } \\
\text { OL, fixed sequence }\end{array}$ & $\begin{array}{l}\text { Single oral doses of AZD5069 } 15 \mathrm{mg}(3 \times 5 \text {-mg oral capsules }) \text { on } 2 \\
\text { occasions, 2nd occasion on Day } 3 \text { of a } 5 \text {-day treatment period with } \\
\text { ketoconazole } 400 \mathrm{mg} \text { daily }\end{array}$ & $\begin{array}{l}13 \text { Caucasian, } 1 \text { Black, } 1 \\
\text { Asian males, median age } \\
33 \text { years (range } 21-44) ; 15 \\
\text { received AZD5069 alone, } 14 \\
\text { received AZD5069 plus } \\
\text { ketoconazole }\end{array}$ \\
\hline $\begin{array}{l}\text { Rel BA } \\
\text { NCT01989520 }\end{array}$ & $\begin{array}{l}\text { Formulation } \\
\text { relative } \\
\text { bioavailability } \\
\text { study } \\
\text { OL, XO, R }\end{array}$ & $\begin{array}{l}2 \times 20 \text {-mg }+1 \times 5 \text {-mg capsules vs } 3 \times 45 \text {-mg tablet formulations } \\
4 \text { single doses }\end{array}$ & $\begin{array}{l}7 \text { Caucasian, } 3 \text { Black and } 6 \\
\text { Asian males, median age } \\
33 \text { years (range } 20-46 \text { ); } 16 \\
\text { received AZD5069 }\end{array}$ \\
\hline
\end{tabular}

$A D M E$ absorption, distribution, metabolism, excretion, bid twice daily, $D B$ double-blind, $D D I$ drug-drug interaction, $O L$ open-label, $P C$ placebocontrolled, $P G$ parallel group, $R$ randomised, $X O$ crossover

\subsubsection{Steady-State 24-h Neutrophil Function Pharmacokinetic Study (NF 24 h PK)}

The primary objectives of the NF $24 \mathrm{~h}$ PK study were to investigate the effect of AZD5069 $100 \mathrm{mg}$ bid on neutrophil number and function in the circulation, and on circulating neutrophil numbers following a burst of strenuous exercise and following subcutaneous injection of granulocyte colony-stimulating factor. The secondary objective was to evaluate the steady-state 24-h pharmacokinetic profile of AZD5069 following twice-daily administration. For the pharmacokinetic analysis, 
comparisons were made between evening and morning administration by frequent blood sampling for $24 \mathrm{~h}$.

\subsubsection{Influence of Food and Age Study (Food and Age)}

The primary objectives of this study were to compare the pharmacokinetics of AZD5069 following administration of single 120-mg doses when fasting or after a high-fat meal, and to make an initial assessment of any pharmacokinetic differences in the fasted state between adult (18-65 years) and elderly ( $>65$ years) subjects. To assess the effect of food, a single dose of AZD5069 was administered to adults either 30 mins after commencing a standard meal or following a fast of at least $10 \mathrm{~h}$ (Part A). The standard meal contained $970 \mathrm{kcal} ; 182,260$ and $529 \mathrm{kcal}$ derived from protein, carbohydrate and fat, respectively, and followed FDA guidelines for a high-fat and high-calorie test meal [17].

In Part B of the study, a single dose of AZD5069 was administered to healthy elderly volunteers in the fasted state for comparison with the fasted adults from Part A of the study.

\subsubsection{Ketoconazole Drug-Drug Interaction Study (DDI)}

The primary objective of this DDI study was to evaluate the effect of ketoconazole on the pharmacokinetics of AZD5069. A single dose of $15 \mathrm{mg}$ AZD5069 was administered to healthy adults followed by once-daily administration of $400 \mathrm{mg}$ ketoconazole with a single dose of $15 \mathrm{mg}$ AZD5069 administered concomitantly on the third day of ketoconazole administration.

\subsubsection{Relative Bioavailability Study (Rel BA)}

The primary objective of the Rel BA study was to assess the relative bioavailability of AZD5069 from the putative phase III tablet formulation in comparison with the capsule formulation used in phase II studies. The secondary objective was to assess the bioavailability of AZD5069 from up to three phase III tablet formulation variants relative to the putative phase III tablet. Subjects received single oral doses of $45 \mathrm{mg}$ AZD5069 as $2 \times 20-\mathrm{mg}+1$ $\times 5$-mg capsules and three different 45 -mg tablet formulations, in a randomised cross-over design.

\subsection{Study Populations}

All subjects who participated in the studies were judged to be healthy, based on standard inclusion and exclusion criteria. An overview of the demographic characteristics of the participants from each study are shown in Table 1.

\subsection{Study Drugs}

AZD5069 was administered in several formulations in these phase I studies. In the SAD, MAD and JSAD/JMAD studies, oral suspensions containing either $1 \mathrm{mg} / \mathrm{g}$ or $50 \mathrm{mg} / \mathrm{g}$ AZD5069 were used. In the Food and Age study, only the $50-\mathrm{mg} / \mathrm{g}$ suspension was used. Capsules containing $5 \mathrm{mg}$ AZD5069 were used in the DDI study to administer a $15-\mathrm{mg}$ dose. For the ADME study, radiolabelled $\left[{ }^{14} \mathrm{C}\right]$ AZD 5069, providing $0.9 \mathrm{MBq} / \mathrm{mL}$, was administered as an oral $5-\mathrm{mg} / \mathrm{mL}$ solution. For the NF $24 \mathrm{~h}$ PK study, AZD5069 was administered as capsules containing $50 \mathrm{mg}$ AZD5069. In the Rel BA study, a 45-mg tablet formulation intended for use in phase III studies, and two other 45-mg tablet formulations with slower dissolution rates were compared with capsules used in a phase II dose-finding study containing $5 \mathrm{mg}$ and $20 \mathrm{mg}$ $(2 \times 20 \mathrm{mg}+1 \times 5 \mathrm{mg})$ of AZD5069.

The ketoconazole (Nizoral ${ }^{\circledR}$ ) administered in the DDI study was a $200-\mathrm{mg}$ tablet manufactured by Janssen-Cilag, Belgium.

\subsection{Collection and Analysis of Pharmacokinetic Samples}

Venous blood, urine and, when required, faeces samples for pharmacokinetic analysis were taken pre-dose and at specified intervals throughout each study. All study samples were analysed within the established stability using fully validated bioanalytical methods in the laboratories of AstraZeneca or, if outsourced, at one of the preferred provider's laboratories on behalf of AstraZeneca.

To investigate the concentration of AZD5069 in human plasma and urine samples, a method that employs protein precipitation (plasma) or dilution (urine) followed by liquid chromatography with tandem mass spectrometric detection (LC-MS/MS) in the positive ion mode was used. The AZD5069 methods (both plasma and urine) were initially validated in the range $1.0-5000 \mathrm{nM}$ with the lower limit of quantification (LLOQ) set at $1.0 \mathrm{nM}$ using $100 \mu \mathrm{L}$ matrix. As the plasma method was transferred to a new bioanalytical provider, the range was slightly adapted to meet the expected sample concentrations to $2.0-4000 \mathrm{nM}$. In addition, a new combined AZD5069 and AZ13587715 (a metabolite) method in the range $1-1000 \mathrm{nM}$ was validated on the same LC/MS/MS platform, using $100 \mu \mathrm{L}$ matrix.

Where appropriate because of concentrations above the upper quantification limit, samples could also be diluted up to 10 times (100 for the combined AZD5069 and AZ13587715 method) with blank human matrix and then quantified within the validated calibration range.

Quality controls (QCs) prepared at three different concentration levels were analysed in duplicate with each 
batch of samples against separately prepared calibration standards to assess the day-to-day performance of the assay. In addition, a dilution QC at one concentration level was analysed with the study samples in all runs where dilution was applied to any of the study samples. The intrabatch and inter-batch precision, reported as coefficient of variation $(\mathrm{CV})$, had to be $\leq 15 \%$ at all levels (except $\leq 20 \%$ at LLOQ) to be acceptable and intra-batch and inter-batch bias had to be within $15 \%$ of the nominal concentration at all levels (except $\pm 20 \%$ at LLOQ). In all of the studies included in this publication, the overall precision for the QC samples (undiluted) at all three concentration levels was $\leq 12.9 \%$ and the overall bias ranged between -6 and $7 \%$. The overall precision for the dilution QC sample was $<12.5 \%$ and the overall bias ranged between -6.8 and $3.5 \%$. In addition, up to $10 \%$ of the study samples in each study were reanalysed to confirm acceptable incurred sample reproducibility of the methods used.

\subsection{Pharmacokinetic Evaluation}

Pharmacokinetic parameters were estimated by non-compartmental analysis using WinNonLin Enterprise Version 5.2 or later (Pharsight Corporation, Mountain View, CA, USA) or SAS ${ }^{\circledR}$ Version 9.2 (SAS Institute Inc., Cary, NC, USA). The plasma parameters assessed for AZD5069 were maximum (peak) drug concentration $\left(C_{\max }\right)$, time to reach maximum concentration $\left(t_{\max }\right)$, area under plasma concentration-time curve from zero to infinity after a single dose (AUC), AUC from zero to time $12 \mathrm{~h}\left(\mathrm{AUC}_{0-12}\right)$, AUC from zero to time $24 \mathrm{~h}\left(\mathrm{AUC}_{0-24}\right)$, AUC during a dose interval at steady state $\left(\mathrm{AUC}_{\mathrm{ss}}\right)$, terminal elimination rate constant $\left(\lambda_{z}\right)$, terminal half-life $\left(t_{1 / 2}\right)$, apparent oral plasma clearance $(\mathrm{CL} / F)$, renal clearance $\left(\mathrm{CL}_{\mathrm{R}}\right)$ and apparent oral volume of distribution during terminal phase $\left(V_{\mathrm{Z}} / F\right)$.

\subsection{Statistical Evaluation}

Statistical analyses were performed using $\operatorname{SAS}^{\circledR}$ Version 8.1 or later. Pharmacokinetic variables were summarised using descriptive statistics. The following factors were assessed by ANOVA as a repeated-fixed effect using point estimates of the geometric least-squares (LS) mean ratios and in some cases associated $90 \%$ confidence intervals (CIs) for AUC (and $C_{\max }$ where applicable): accumulation $\left(\mathrm{AUC}_{0-12}\right.$ [or $\mathrm{AUC}_{0-24}$ ] after multiple dosing to $\mathrm{AUC}_{0-12}$ [or $\mathrm{AUC}_{0-24}$ ] after the first dose), time dependency $\left(\mathrm{AUC}_{\mathrm{ss}}\right.$ to $\mathrm{AUC}_{0-12}$ [or $\mathrm{AUC}_{0-24}$ ] after the first dose), diurnal variability (evening to morning), fed to fasted, elderly to adults and tablet to capsule. Time to steady state was assessed by visual inspection of graphs of individual trough concentrations $\left(C_{12 \mathrm{~h}}\right)$ over time. Dose-proportionality analysis was conducted using data from the SAD and MAD studies. Since there are single-dose data included in the MAD study, these data were pooled with the single-dose data collected in the SAD study. This analysis was repeated for each of single-dose (Day 1) AUC and $C_{\max }$ and the corresponding AUC and $C_{\max }$ following multiple dosing (Day 8). Dose proportionality was assessed using a power model that, while presented on a linear scale, was based on a linear regression model of log-transformed AUC (and $C_{\max }$ separately) as a function of log-transformed dose. The model was then presented on a linear scale as:

AUC $=\exp ^{\text {intercept }} \cdot d o s e^{\text {slope }}$. The $90 \%$ CI for the slope estimate is also presented along with the adjusted correlation coefficient $\left(\mathrm{R}^{2}\right)$.

Pharmacokinetic differences between Japanese and Caucasian subjects were assessed by comparing geometric mean ratios (GMRs) of dose-normalised AUC and $C_{\max }$ values and by graphs of exposure across all dose levels.

AUC and $C_{\max }$ inter- and intra-subject components of variability were estimated with a mixed-effect analysis (ANOVA) model for the values on Days 6 and 8, with subject as a random effect, for each dose group (MAD study). Similarly, the variability components were estimated with a fixed-effect analysis (ANOVA) model for the values on Day 3 (morning and evening), with subject as a fixed effect in the NF 24 h PK study.

For most studies (SAD, MAD, JSAD/MAD, Food and Age, ADME, NF $24 \mathrm{~h}$ PK), the sample sizes were based on previous experience from similar studies with other compounds and were determined without formal statistical considerations, hypotheses or formal power calculations. For the DDI study, the variability observed in the MAD study was used: the log scale standard deviation (SD) for $C_{\max }$ and AUC were 0.298 and 0.134, respectively, for the pooled doses. Based on a 90\% CI (two one-sided testing procedure at 5\% type I error level for each test), 12 patients for AUC and 18 patients for $C_{\max }$ would yield $>90 \%$ power to declare no effect based on default $0.8-1.25$ noeffect boundaries. For the Rel BA study, the variabilities observed in the MAD, DDI and NF $24 \mathrm{~h}$ PK studies were used for sample size estimation: within-subject log-scale SD ranged from 0.03 to 0.14 for AUC and 0.16 to 0.22 for $C_{\max }$. Assuming an observed ratio of 1 in the AUC and $C_{\max }$ between two treatments and a within-subject SD of 0.1 (AUC) and $0.2\left(C_{\max }\right)$ on the log scale, corresponding 90\% CIs for the treatment ratios are 0.93-1.08 and $0.86-1.16$, respectively. 


\section{Results}

A summary of the pharmacokinetic parameters from all of the phase I studies is presented in Supplementary Table S1 (see ESM). Dose-normalised AUC values are shown in Fig. 1.

\subsection{Plasma Concentration Profile}

Following an oral single dose of an AZD5069 suspension to fasting healthy subjects, the peak plasma concentration $\left(C_{\max }\right)$ was observed at approximately $2 \mathrm{~h}$. The concentration declined in a multi-exponential manner with approximate initial and terminal half-lives of 4 and $11 \mathrm{~h}$, respectively (Fig. 2).

a

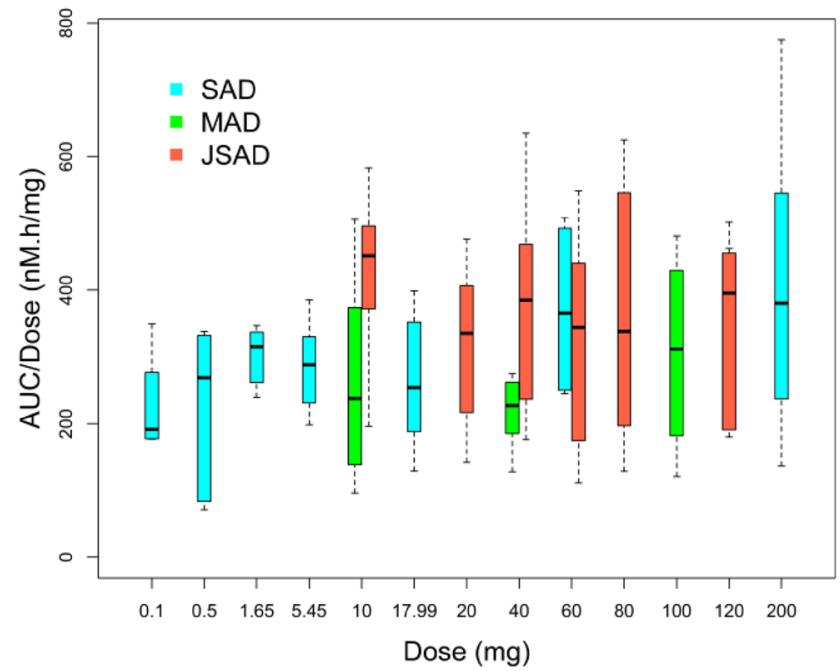

b

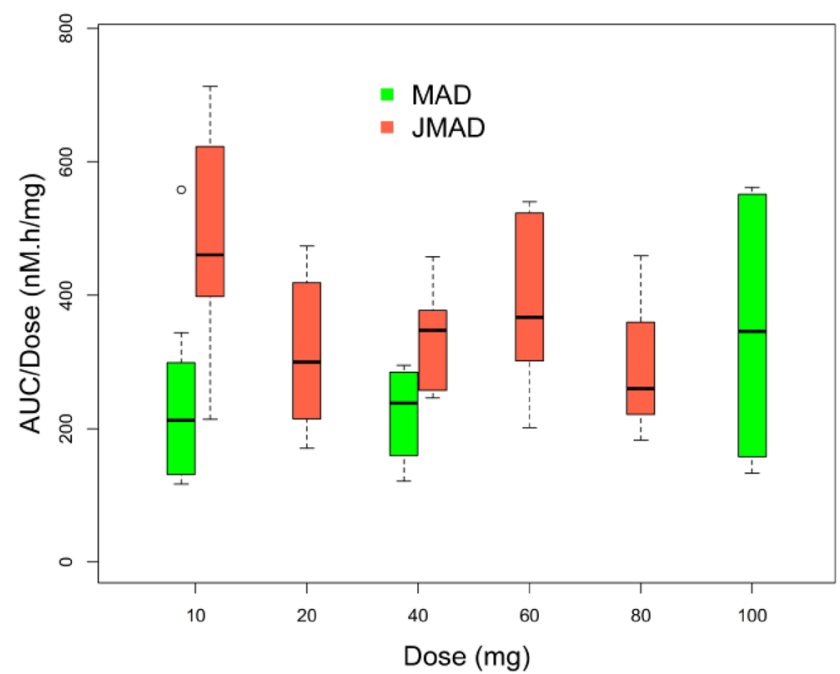

\subsection{Absorption}

AZD5069 was well absorbed as $65 \%$ of the radioactivity was found in urine following a single 100-mg oral dose of $\left[{ }^{14} \mathrm{C}\right] \mathrm{AZD} 5069$ solution (ADME study). Absorption from the oral solution was rapid with $C_{\max }$ being reached at a median time of $0.5 \mathrm{~h}$ after administration (ADME study). AZD5069 was also relatively quickly absorbed from an oral suspension during fasting conditions in healthy subjects (median $t_{\max } 2 \mathrm{~h}$ (range $0.5-4 \mathrm{~h}$ ), and this was independent of the dose administered (SAD study). The rate and extent of absorption of AZD5069 when administered as capsules was similar to that with the oral suspension (Fig. 1a, Table S1 [ESM]). Geometric mean AUC, $C_{\max }$ and median $t_{\max }$ were $8390 \mathrm{nmol} \mathrm{h} / \mathrm{L}, 2210 \mathrm{nmol} / \mathrm{L}$ and $2.0 \mathrm{~h}$ after $40 \mathrm{mg}$ AZD5069 in suspension (MAD study,
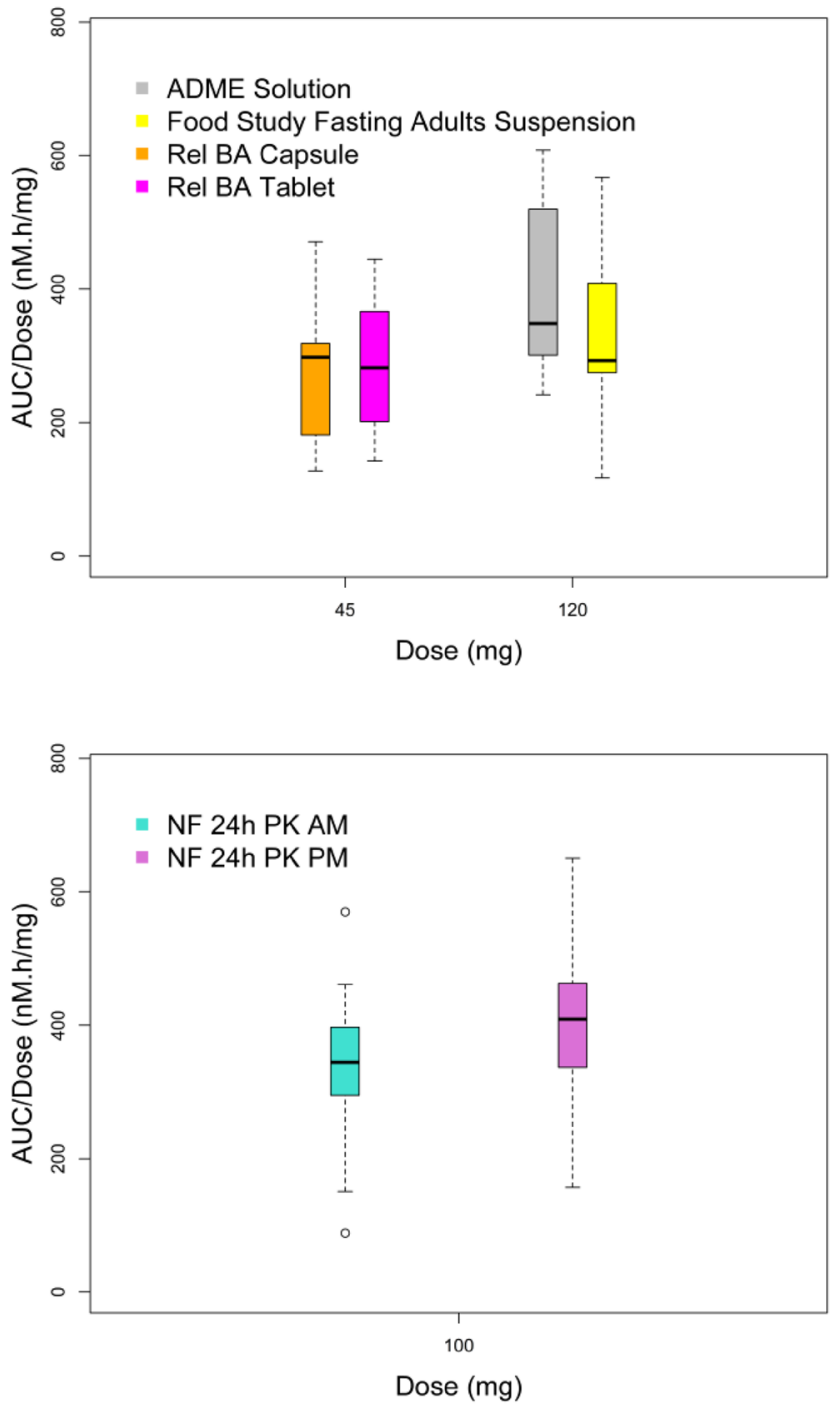

Fig. 1 Boxplots of dose-normalised AUC (area under plasma concentration-time curve) by dose and study (see Table 1 for acronyms) following: a single-dose; and $\mathbf{b}$ repeated-dose (bid) administration of AZD5069 
Fig. 2 Arithmetic mean plasma AZD5069 concentration-time profiles following a single oral administration of $0.1-200 \mathrm{mg}$ (SAD study). Inserted graph shows the same data on a logarithmic $y$-axis scale

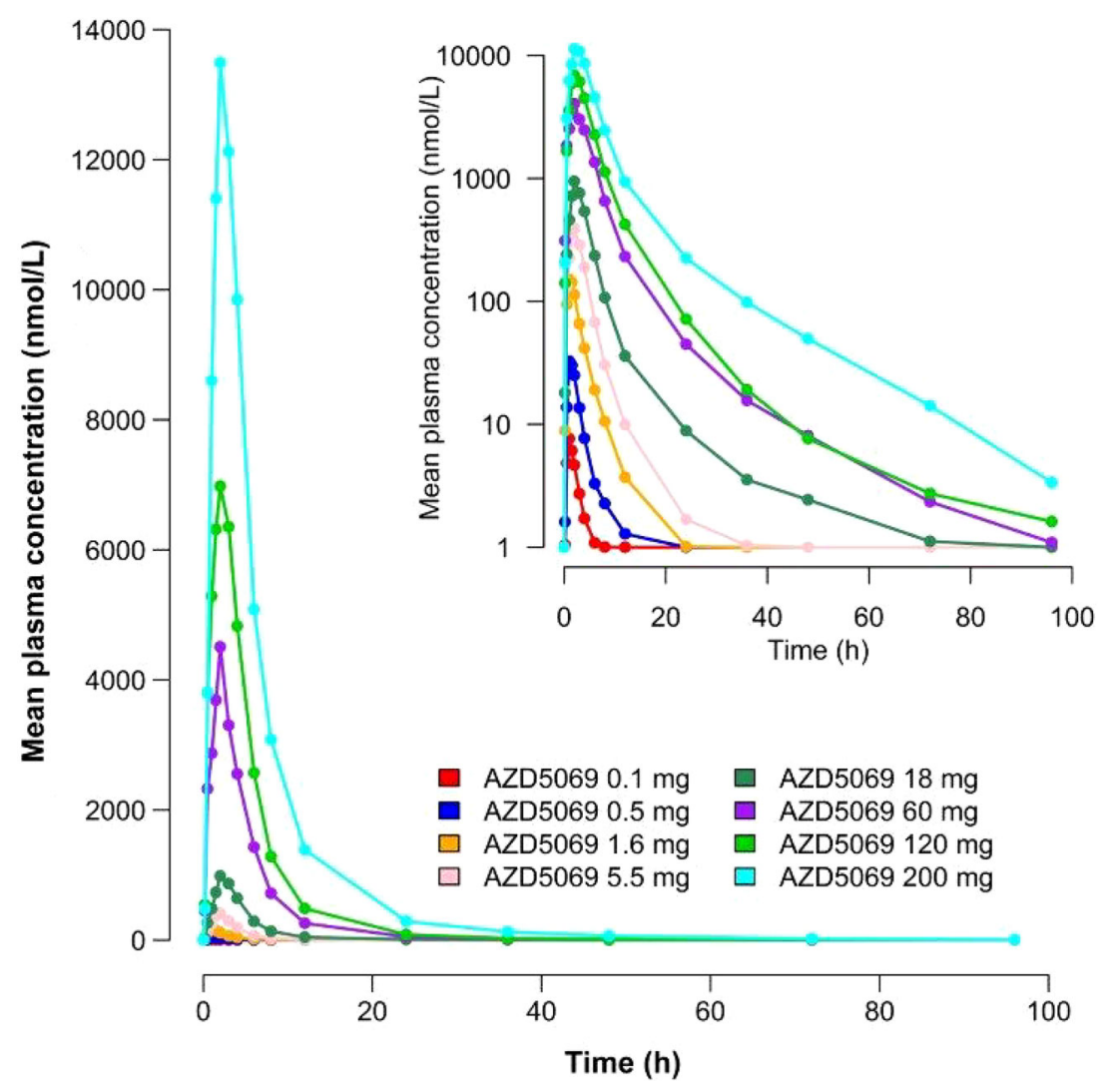

Day 1) compared with $11,500 \mathrm{nmol} \mathrm{h} / \mathrm{L}, 2610 \mathrm{nmol} / \mathrm{L}$ and $3.0 \mathrm{~h}$ after $45 \mathrm{mg}$ in capsules (Rel BA study).

\subsection{Distribution}

The geometric mean apparent oral volume of distribution $\left(V_{\mathrm{z}} / F\right)$ ranged from 56 to $134 \mathrm{~L}$ at relevant doses across studies in adult Caucasian subjects.

\subsection{Elimination}

The total apparent plasma clearance $(\mathrm{CL} / F)$ was estimated to be approximately $8 \mathrm{~L} / \mathrm{h}$ (mean across all studies in adult Western subjects). CL/F appeared to be independent of dose with mean values of $10.8,10.4$ and $8.85 \mathrm{~L} / \mathrm{h}$ in the 10-, 40- and 100-mg dose groups on Day 1, respectively, and 11.0, 10.4 and 8.23 L/h on Day 8, respectively (MAD study). Renal clearance $\left(C_{R}\right)$ also appeared to be independent of dose with mean values of $0.270,0.302$ and $0.245 \mathrm{~L} / \mathrm{h}$ in the 10-, 40- and 100-mg dose groups on Day 1, respectively, and $0.367,0.352$ and $0.386 \mathrm{~L} / \mathrm{h}$ on Day 8 , respectively (MAD study). The fraction of the AZD5069 dose excreted unchanged thus ranged from 2.5 to $4.7 \%$.

Following administration of a single 120-mg dose of $\left[{ }^{14} \mathrm{C}\right]$ AZD5069 as an oral solution, excretion via urine was the primary route of elimination ( $65 \%$ of dose) with faecal elimination accounting for the remaining 35\% of the dose (ADME study). AZD5069 is likely to be extensively metabolised in humans as the fraction of an oral dose excreted as unchanged drug in urine was $<10 \%$ (SAD study, MAD study, ADME study). Extensive metabolism was also indicated by mean plasma radioactivity equivalent concentrations being greater than mean AZD5069 plasma concentrations at all sampling times following ingestion of $\left[{ }^{14} \mathrm{C}\right]$ AZD5069 solution (ADME study).

\subsection{Steady-State Pharmacokinetics}

Steady-state conditions were attained within 2-3 days of bid dosing (MAD study). The mean accumulation ratio was 1.07-1.19 on Day 6 and 1.01-1.26 on Day 8 following bid dosing (MAD study).Total AUC after the first dose was similar in magnitude to AUC during a dose interval at steady state $\left(\mathrm{AUC}_{0-12}\right)$, indicating time-independent pharmacokinetics. The variability in AUC was moderate between subjects: $29-62 \% \mathrm{CV}$ in the MAD study, and 64\% $\mathrm{CV}$ in the NF $24 \mathrm{~h}$ PK study, and very low between dosing occasions within subjects $(3-11 \% \mathrm{CV}$ in the MAD study and $8 \% \mathrm{CV}$ in the NF $24 \mathrm{~h}$ PK study). Corresponding $C_{\max }$ values were $13-35$ and $44 \%$ for the inter-subject variability and $19-22$ and $16 \%$ for the intra-subject variability. 


\subsection{Diurnal Variability}

The geometric mean plasma concentration of AZD5069 observed at $12 \mathrm{~h}$ post-dose $\left(C_{12}\right)$ was greater for the evening dose $(564 \mathrm{nmol} / \mathrm{L})$ compared with the morning dose $(459 \mathrm{nmol} / \mathrm{L})$ and median $t_{\mathrm{ss}, \max }$ was $1 \mathrm{~h}$ later after the evening dose (NF $24 \mathrm{~h}$ PK study). The $90 \%$ CIs of the evening:morning ratios for the exposure parameters were, however, all within the default bioequivalence boundaries of $0.80-1.25$; the $\mathrm{AUC}_{0-12, \mathrm{ss}}$ ratio was 1.17 (90\% CI $1.13-1.21), C_{\mathrm{ss}, \max }$ ratio $1.15(90 \%$ CI $1.07-1.24)$, and $C_{\mathrm{ss}}$, min ratio 1.01 (90\% CI 0.99-1.03).

\subsection{Dose Linearity}

AUC and $C_{\max }$ were approximately proportional to the AZD5069 dose following both single $(0.1-200 \mathrm{mg})$ and repeated (10-100 mg bid) administration (Fig. 3).
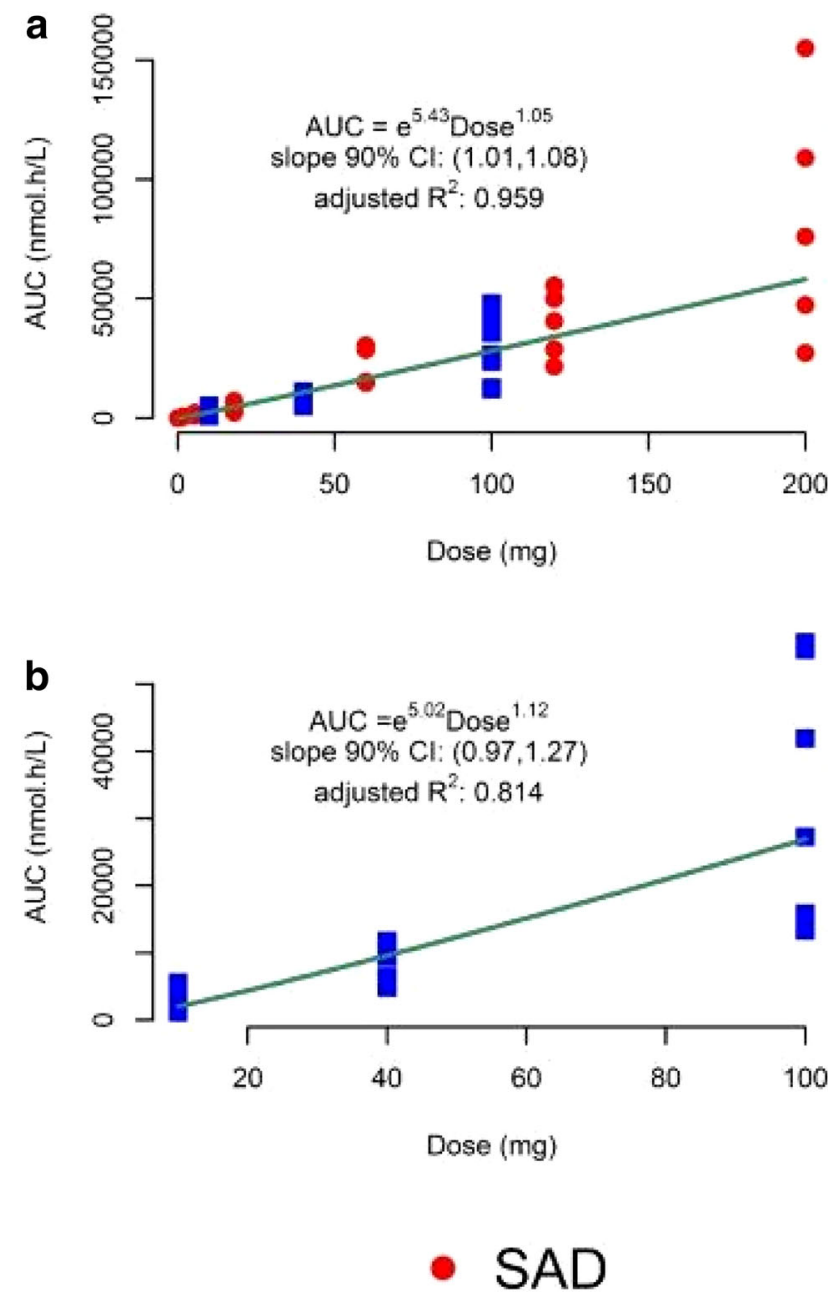

Fig. 3 AUC and $C_{\max }$ versus dose following single-dose (a) and repeated-dose (bid) (b) administration of AZD5069. Red symbols represent data from the SAD study and blue symbols from the MAD

\subsection{Pharmacokinetics in Populations of Special Interest}

Elderly (median 68 [range 65-77] years) healthy Caucasian subjects had, on average, 39\% higher AUC (90\% CI 4-85) and $21 \%$ higher $C_{\max }(90 \% \mathrm{CI}-4$ to 54$)$ values for AZD5069 than younger subjects (median 30 [range 23-57] years) (Food and Age study).

Healthy Japanese subjects appeared to have similar, or higher, exposure to AZD5069 compared with Caucasian subjects, depending on the study and dose level being investigated (Fig. 1). Geometric mean AUC ratios (Japanese:Caucasians) for AZD5069 varied between 0.80 and 1.06 when Japanese SAD data were compared with Western SAD data at equal doses (JSAD/JMAD study, SAD study). When comparing Japanese SAD/MAD AZD5069 data with Western MAD data at equal doses, the exposure was higher in Japanese subjects, after both the first dose and repeated dosing (JSAD/JMAD study, MAD study).
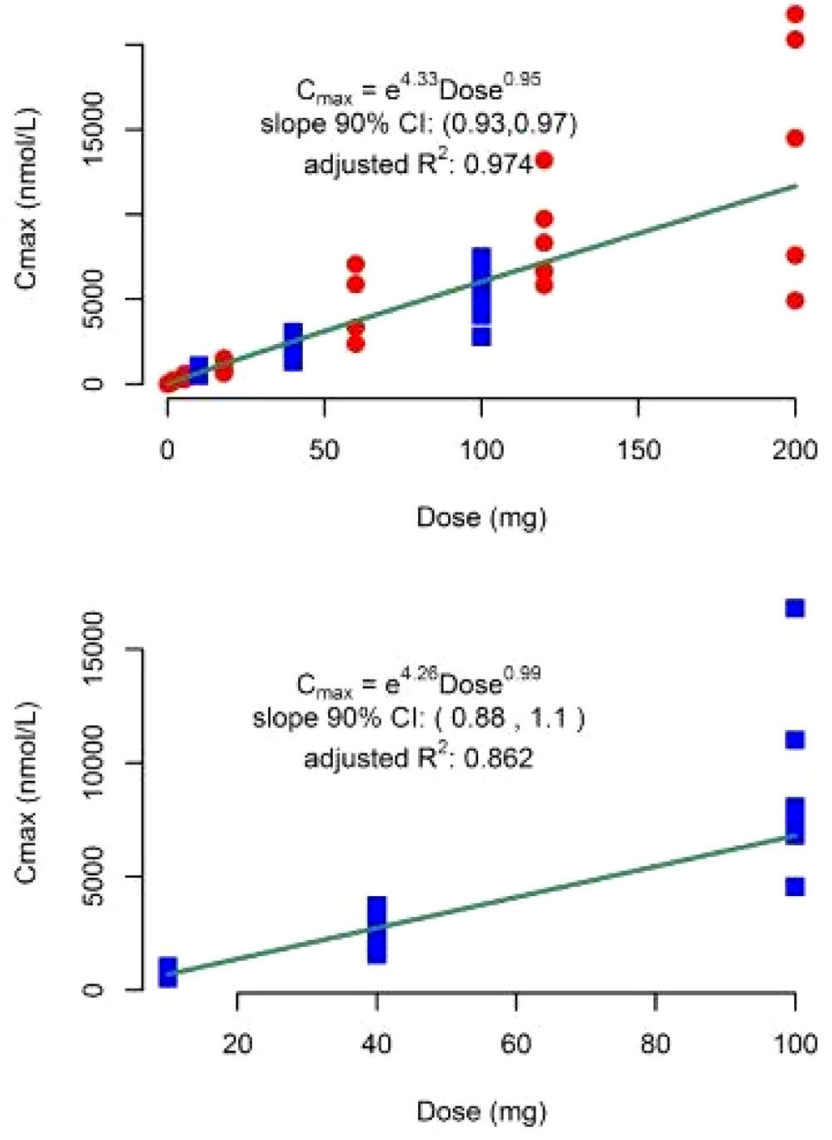

- MAD

study. Lines and equations are based on regression analysis (see Sect. 2.6 for details). AUC area under plasma concentration-time curve, $C_{\max }$ peak plasma concentration 
Geometric mean ratios varied between 1.20 and 1.97 . When pooling all AZD5069 doses, the dose-normalised AUC at steady state was $40 \%$ higher in the Japanese subjects.

Smokers, who were only included in the MAD study, had generally somewhat lower dose-normalised AUC values than non-smokers from the SAD study, but similar to those from the NF $24 \mathrm{~h}$ PK study and the fasted adults in the Food and Age study (Fig. 1).

\subsection{Drug-Food and Drug-Drug interactions}

Administration of AZD5069 oral suspension immediately after a high-fat meal resulted in a $50 \%$ lower $C_{\max }$, which was delayed by $3 \mathrm{~h}$ in comparison with administration during the fasting state; however, the fed:fasted AUC ratio was within the standard bioequivalence boundaries 80-125\% (Food and Age study). The fed:fasted geometric mean ratio for AZD5069 AUC was 0.89 (90\% CI $0.83-0.94)$, while for $C_{\max }$ it was 0.50 (90\% CI 0.40-0.61).

The mean concentration-time profile following administration of AZD5069 with the CYP3A4 inhibitor ketoconazole was higher than when AZD5069 was administered alone, from the first quantifiable sample at 30 mins post-dose. In most subjects, AZD5069 plasma concentrations dropped below the LLOQ by 48 and $72 \mathrm{~h}$ postdose in the AZD5069 and AZD5069 + ketoconazole treatment groups, respectively (Fig. 4). Co-administration of AZD5069 and ketoconazole resulted in a 2.1-fold increase in AUC (90\% CI 1.9-2.3) and a 1.6-fold (90\% CI 1.5-1.9) increase in $C_{\max }$ for AZD5069.

\subsection{Formulation Factors}

The relative bioavailability study showed similar AUC for all formulations tested, but the AZD5069 absorption was slightly faster from the intended phase III tablet formulation than from the capsule formulation used in the phase II studies. Geometric LS mean for AZD5069 AUC (nmol*h/ L) was $11,570(95 \%$ CI $9425-14,200)$ for the phase II capsules compared with 12,080 (95\% CI 9846-14,820) for the intended phase III tablet formulation. AUC geometric LS mean values for the two slower dissolution tablets were $10,710$ (95\% CI $8725-13,140)$ and 10,870 (95\% CI 8861-13,350), respectively. The geometric mean ratio of tablet:capsule formulations was 1.04 (90\% CI 0.99-1.10) for AUC and 1.20 (90\% CI 1.05-1.38) for $C_{\max }$. The tablet and capsule formulations of AZD5069 were considered pharmacokinetically comparable. Overall, there were no consistent differences in AUCs between the studies that could be related to formulation (Fig. 1a), suggesting that the solid formulations of AZD5069 had similar bioavailability to the liquid formulations.
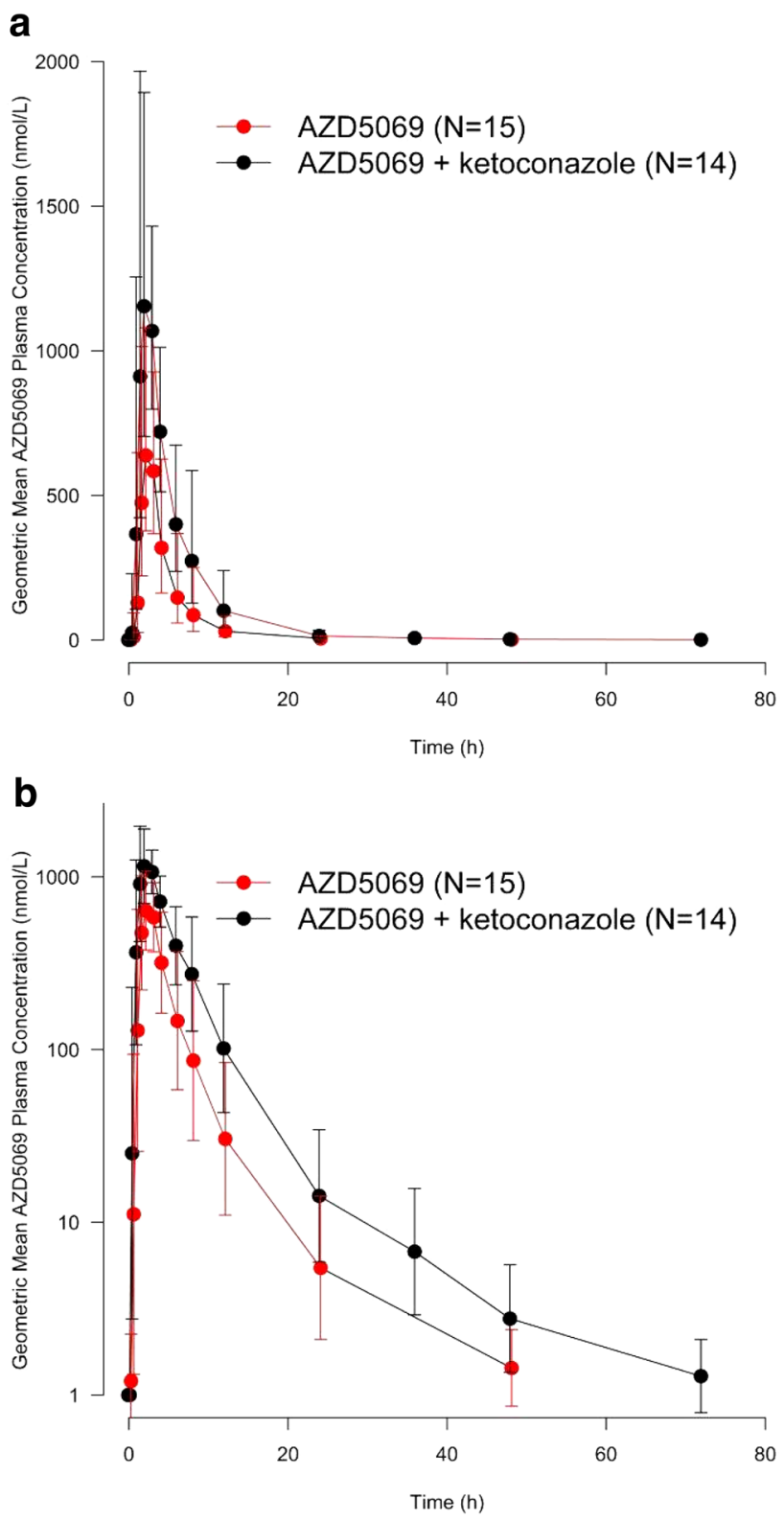

Fig. 4 Geometric mean $( \pm S D)$ plasma concentration versus time profiles of AZD5069 when administered alone on Day 1 and in combination with ketoconazole on Day 3 of a 5-day treatment period with ketoconazole $400 \mathrm{mg}$ daily (DDI study) on a linear scale (a) and a $\log$ scale (b)

\section{Discussion}

These studies provide a comprehensive portrait of the pharmacokinetic profile of AZD5069 in healthy human volunteers. AZD5069 is rapidly absorbed during fasting conditions; administration with food delays and reduces the peak plasma concentration, but the total exposure (AUC) remains unchanged.

The plasma concentration profile of AZD5069 has a terminal half-life of $11 \mathrm{~h}$, which supports twice-daily 
administration. Steady state is achieved within $2-3$ days and no major time dependency is observed in the pharmacokinetic profile. Systemic exposure to AZD5069 is approximately proportional to the dose following both single and repeated dosing. In a 6-month study in patients with severe asthma, plasma exposure of AZD5069 was approximately proportional to the dose across the range evaluated (5-45 mg bid) and the morning pre-dose plasma levels were consistent over the time period investigated (1 week to 6 months) [14].

AZD5069 is extensively metabolised in humans, with $<10 \%$ of the oral dose excreted unchanged. In vitro data have indicated that the oxidative metabolism of AZD5069 is primarily mediated by CYP3A4 and CYP2C9 isozymes, but other metabolic pathways (for example, glucuronidation) may also play a significant role [4]. Based on ex vivo studies, AZD5069 is extensively bound (99\%) to plasma proteins and does not enter into red blood cells (blood:plasma ratio $=0.56$ ) (AstraZeneca, data on file). $\mathrm{CL} / F$ data thus suggest that AZD5069 is a low-clearance drug (extraction ratio $<0.18$ ). Assuming that the fraction absorbed is at least $65 \%$ and the absolute bioavailability is more than $50 \%$, the renal clearance can be estimated to be $<20 \%$ of the total clearance. This suggests that the elimination of AZD5069 is not likely to be sensitive to differences in renal function, but that hepatic function might be relevant. Japanese subjects appeared to have similar, or somewhat higher, exposure to AZD5069 than Caucasian subjects, depending on the study and dose level. The pharmacokinetic variability within subjects was very low, while between-subject variability was moderate.

There was no obvious influence of smoking on the AZD5069 exposure, but the results should be interpreted with caution as smokers and non-smokers were not included in the same study. Smoking was, however, not expected to be an influential factor, as AZD5069 is not metabolised by any of the iso-enzymes known to be induced by smoking, i.e. CYP1A2 or CYP2B6 [18]. Coadministration with the potent CYP3A4 inhibitor ketoconazole resulted in an increase in AZD5069 AUC and $C_{\max }$ of 2.1- and 1.6-fold, respectively. The $<5$-fold increase indicates that AZD5069 is not a sensitive substrate of CYP3A4 [19]. The clinical relevance of this remains, however, to be assessed and will depend on the selected clinical dose and the safety margins at this dose. Until the therapeutic window has been characterised in the target patient population, we have taken a cautious approach, recommending that AZD5069 should not be combined with potent CYP3A4 inhibitors in clinical studies.

\section{Conclusion}

AZD5069 demonstrated a predictive, linear pharmacokinetic profile with low intra- and moderate inter-subject variability and no major influences from ethnicity, age, food or formulation. The estimated half-life indicated suitability for twice-daily administration in future clinical development to assess the therapeutic potential of AZD5069.

Acknowledgements We thank all the participants, investigators and trial-site staff who were involved in the conduct of these trials. We also thank David Candlish, InScience Communications, for medical writing and editorial assistance. Our thanks to the Bioanalytical laboratories for analysing the samples from the clinical trials included in the manuscript. Many thanks to Xiao Tong for programming contributions.

\section{Compliance with Ethical Standards}

Funding All studies were sponsored and funded by AstraZeneca. David Candlish, of InScience Communications, Tattenhall, UK, provided editorial and medical writing assistance, which was funded by AstraZeneca.

Conflicts of Interest All authors are full-time permanent employees of AstraZeneca.

Ethical Approval All procedures performed in studies involving human participants were in accordance with the ethical standards of the institutional and/or national research committee and with the 1964 Helsinki declaration and its later amendments or comparable ethical standards.

Informed Consent Informed consent was obtained from all individual participants included in the studies.

Open Access This article is distributed under the terms of the Creative Commons Attribution-NonCommercial 4.0 International License (http://creativecommons.org/licenses/by-nc/4.0/), which permits any noncommercial use, distribution, and reproduction in any medium, provided you give appropriate credit to the original author(s) and the source, provide a link to the Creative Commons license, and indicate if changes were made.

\section{References}

1. Gernez Y, Tirouvanziam R, Chanez P. Neutrophils in chronic inflammatory airway diseases: can we target them and how? Eur Respir J. 2010;35(3):467-9.

2. Nair P, Aziz-Ur-Rehman A, Radford K. Therapeutic implications of 'neutrophilic asthma'. Curr Opin Pulm Med. 2015;21(1):33-8.

3. Nicholls D, Wiley K, Dainty I, MacIntosh F, Phillips C, Gaw A, Kärrman Mårdh C. Pharmacological characterization of AZD5069, a slowly reversible CXC chemokine receptor 2 antagonist. J Pharmacol Exp Ther. 2015;353(2):340-50.

4. Gardiner P, Ekdahl A, Palmgren A-P, Cullberg M, Larsson B. The mechanisms and routes of clearance of the CXCR2 antagonist AZD5069 in human. American Association of Pharmaceutical Scientists (AAPS); San Antonio, Texas, USA. 2013. 
5. Wray H, Sparrow A. Safety and tolerability of single doses of AZD5069 in healthy volunteers. Eur Respir J. 2011;38(Supplement 55):3984.

6. Wray H, Wilbraham D. Safety and tolerability of AZD5069 in healthy smokers following multiple ascending doses. Int $\mathrm{J}$ Immunorehab. 2012;14(1):78.

7. Lorch U, Negi H, Tabata H, Wray H, Cullberg M, Larsson B. The safety, tolerability and pharmacokinetics of AZD5069, a novel CXCR2 antagonist, in healthy Japanese volunteers. Eur Respir J. 2012;40(Supplement 56):P4842.

8. Mant T, Wray H, Cullberg M, Larsson B. The absorption, distribution, metabolism and excretion (ADME) of single oral doses of AZD5069, a novel CXCR2 antagonist, in healthy male volunteers. Eur Respir J. 2012;40(Supplement 56):P2149.

9. Jurcevic S, Humfrey C, Uddin M, Warrington S, Larsson B, Keen C. The effect of a selective CXCR2 antagonist (AZD5069) on human blood neutrophil count and innate immune functions. $\mathrm{Br} \mathrm{J}$ Clin Pharmacol. 2015;80(6):1324-36.

10. Wray H, Mant T. Effects of food and age on pharmacokinetics, safety and tolerability of single doses of AZD5069. Int J Immunorehab 2012;14(1):78.

11. Cullberg M. Effect of the CYP3A4 inhibitor ketoconazole on the pharmacokinetics and pharmacodynamics of AZD5069, an oral CXCR2 antagonist. Eur Respir J. 2014;44(Supplement 58):P961.

12. De Soyza A, Pavord I, Elborn JS, Smith D, Wray H, Puu M, Larsson B, Stockley R. A randomised, placebo-controlled study of the CXCR2 antagonist AZD5069 in bronchiectasis. Eur Respir J. 2015;46(4):1021-32.

13. Kirsten A, Forster K, Radeczky E, Linnhoff A, Balint B, Watz H, Wray H, Salkeld L, Cullberg M, Larsson B. The safety and tolerability of oral AZD5069, a selective CXCR2 antagonist, in patients with moderate-to-severe COPD. Pulm Pharmacol Ther. 2015;31:36-41.

14. O'Byrne P, Metev H, Puu M, Richter K, Keen C, Uddin MK, Larsson B, Cullberg M, Nair P. Efficacy and safety of a CXCR2 antagonist, AZD5069, in patients with uncontrolled persistent asthma receiving ICS/LABA therapy: a phase $2 b$ randomised trial Lancet. Respir Med. 2016;4(10):797-806.

15. Watz H, Uddin M, Pedersen F, Kirsten A, Goldmann T, Stellmacher F, Groth E, Larsson B, Bottcher G, Malmgren A, Kraan M, Rabe KF. Effects of the CXCR2 antagonist AZD5069 on lung neutrophil recruitment in asthma. Pulm Pharmacol Ther. 2017;45:121-3.

16. Hong D, Falchook G, Cook CE, Harb W, Lyne P, McCoon P, Mehta M, Mitchell P, Mugundum GM, Scott M, Wang JS. A phase 1b study (SCORES) assessing safety, tolerability, pharmacokinetics, and preliminary anti-tumor activity of durvalumab combined with AZD9150 or AZD5069 in patients with advanced solid malignancies and SCCHN. Ann Oncol. 2016;27(supplement 6): 1049PD.

17. US Dept of Health and Human Services, Food and Drug Administration, Center for Drug Evaluation and Research (CDER). Guidance for Industry. Food-Effect Bioavailability and Fed Bioequivalence Studies. 2002.

18. Lucas C, Martin J. Smoking and drug interactions. Aust Prescrib. 2013;36(3):102-4.

19. U.S. Department of Health and Human Services Food and Drug Administration (FDA) Center for Drug Evaluation and Research (CDER) Center for Biologics Evaluation and Research (CBER). Guidance for industry: drug interaction studies-study design, data analysis, and implications for dosing and labeling recommendations. 2012. 